\title{
Lost in the library? Stop floundering-follow the fish
}

\author{
By Kathryn Graves
}

\section{Appealing displays increase awareness of library resources}

1. $t$ the University of Kansas (KU), Watson Library, the Bibliographic Instruction Group in the Reference Department (BIRDS) opened an exhibit for the Fall 1992 semester, entitled "Lost in the Library? Stop Floundering and Follow the Fish." The purpose of the exhibit was to feature the expanding library instruction program and an expert system called Reference Assistant. Displays in six cases all follow the fish theme. This theme, with delightful illustrations by student assistant Joel R. Cooper, has proven to be eyecatching and attracts attention to this instructional exhibit.

\section{Presenting the research strategy}

The first case presents a library research strategy that recommends consulting general information sources (such as encyclopedias and the library catalog) for a background overview, then specialized sources as the focus is narrowed to a specific topic. It also recommends checking indexes to

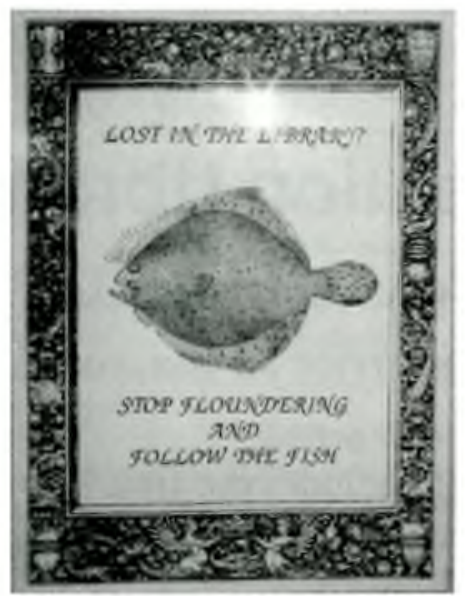

Drawings by student assistant Joel R. Cooper attract attention to this instructional exhibit.
In the expanded library instruction program the BIRDS offer a variety of options for learning about KU's library resources. One case, entitled "How to Learn about the Library," exhibits schools of fish pursuing these options. Some fish are taking a guided tour. These may be general orientation tours or faculty-scheduled course-integrated sessions on a particular subject, at a beginning or advanced level. Other fish are shown using a printed self-guided tour while still others are taking a self-guided audiotape tour. The audiotape follows a librarian through an instructional session with two new students/library users. Listeners can stop the tape as they actually experiment with the online catalog or walk from one area of the building to another in this step-by-step instruction.

Schools of fish viewing a computer screen illustrate that demonstrations of electronic databases are available. For small groups, these demonstrations are held at the reference department workstations; larger groups meet in the Anschutz Science Library's conference room that has a computer projection panel. One case displays sample CD-ROMs, explaining that these include indexes and full-text databases which access journal and book information.

Two cases hold "Subject Guides to Library Use." In these cases are included published bibliographies and guides to research on specific 
subjects such as linguistics, religion, psychology, German studies, and cultural anthropology. Also displayed are many of the printed "Guides for Readers" prepared by KU librarians. These guides are annotated lists of directories, biographies, bibliographies, indexes and abstracts, almanacs, and statistical sources which are available in the $\mathrm{KU}$ libraries. the organization and visual appeal of the exhibit as well as by the variety of instructional programs offered and the resources available. In addition to its instructional purpose, it is a public awareness exhibit in that it introduces new programs and the Reference Assistant expert system, and increases awareness of the electronic databases.

\section{Increasing awareness of censorship}

The final case displays banned books and is illustrated by a blindfolded fish. With the cooperation of faculty and teaching assistants in the English department, the BIRDS created an assignment on censorship. The banned books display corresponds with one of the many types of censorship which the students research. Each book displayed is accompanied by an annotation explaining when and where the book was challenged, seized, suppressed, destroyed or banned.

\section{Introducing an electronic expert system}

Keeping with the fish theme, the Reference Assistant expert system features a screen saver with travelling fish (from the "Screen Peace" software). Reference Assistant directs researchers to frequently needed reference books without the help of a reference librarian. The hypertext system uses a mouse to advance the user from the main menu to a type of source to a particular book with its call number, and finally to a floor plan showing the shelf or index table location of specific books in the reference collection. The Reference Assistant computer was donated by the KU Friends of the Library.

This exhibit has attracted the attention of many students, faculty, and our own library staff. People are impressed by

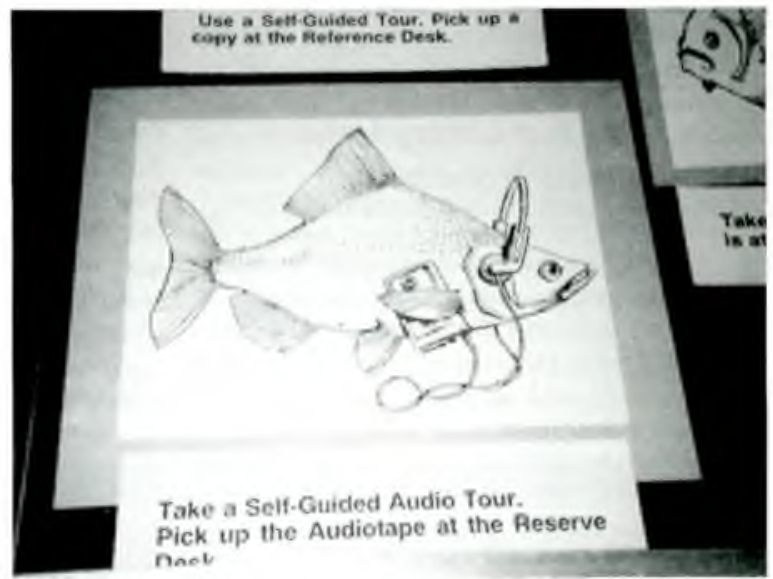

This is an example of the fish motif used in Watson Library's eyecatching instructional exhibit. It draws attention to their expanding library instruction program and an expert system called Reference Assistant.

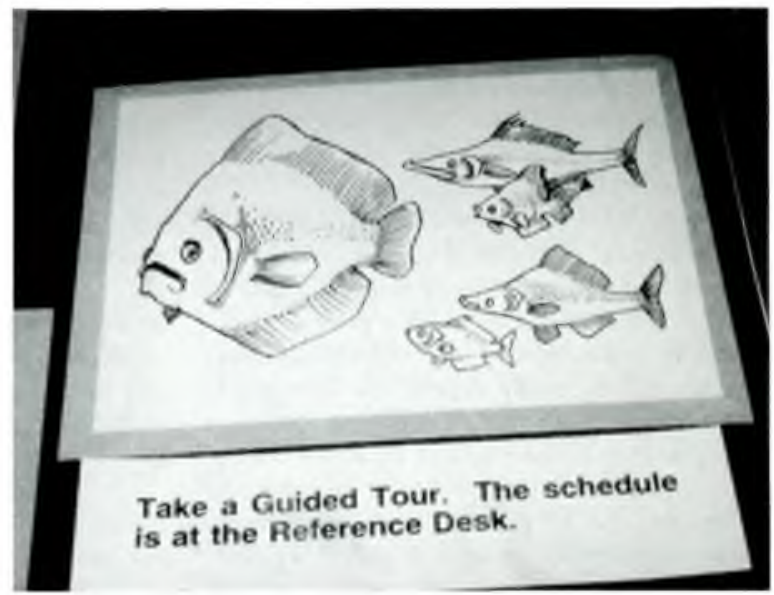

This is another section of the exhibit using the fish theme to publicize the library's resources. The exhibit has increased awareness of the electronic databases. 